diverters for a better understanding of comparative safety and effectiveness among the different devices.

Disclosures M. Waqas: None. R. Dossani: None. M. Alkhaldi: None. J. Neveu: None. J. Cappuzzo: None. J. Liam: None. A. Khan: None. V. Lazarov: None. A. Monteiro: None. J. Davies: 1; C; National Center for Advancing Translational Sciences of the National Institutes of Health under award number KL2TR001413 to the University at Buffalo. A. Siddiqui: 2; C; Amnis Therapeutics, Boston Scientific, Canon Medical Systems USA Inc., Cerebrotech Medical Systems Inc., Cerenovus, Corindus Inc., Endostream Medical Ltd., Imperative Care, Inc. Integra LifeSciences C. 4; C; Adona Medical, Inc, Amnis Therapeutics, (Purchased by Boston Scientific October 2017), Blink TBI Inc., Buffalo Technology Partners Inc., Cerebrotech Medical Systems, Inc., Cognition Medical, Endostrea. E. Levy: 2; C; Claret Medical, GLG Consulting, Guidepoint Global, Imperative Care, Medtronic, Rebound, StimMed;. 4; C; NeXtGen Biologics, RAPID Medical, Claret Medical, Cognition Medical, Imperative Care (formerly the Stroke Project), Rebound Therapeutics, StimMed, Three Rivers Medical.

\section{E-130 USE OF WALRUS BALLOON GUIDE CATHETER FOR PROXIMAL FLOW ARREST DURING NEUROINTERVENTIONAL PROCEDURES}

${ }^{1} \mathrm{R}$ Dossani, 'M Waqas, ${ }^{1} \mathrm{~A}$ Baig*, ${ }^{2} \mathrm{D}$ Popoola, ${ }^{1} \mathrm{~J}$ Cappuzzo, ${ }^{1} \mathrm{H}$ Rai, ${ }^{1} \mathrm{~A}$ Monteiro, ${ }^{3} \mathrm{~A}$ Levy, ${ }^{3} \mathrm{E}$ Hashmi, ${ }^{1} \mathrm{~J}$ Davies, ${ }^{1} \mathrm{E}$ Levy, ${ }^{1} \mathrm{~A}$ Siddiqui. ${ }^{1}$ Neurosurgery, University at Buffalo Neurosurgery, Buffalo, NY; ${ }^{2}$ Neurosurgery, Jacobs School of Medicine and Biomedical Sciences, Buffalo, NY; ${ }^{3}$ Neurosurgery, Gates Vascular Institute at Kaleida Health, Buffalo, NY

\subsection{6/neurintsurg-2021-SNIS.225}

Introduction The use of balloon guide catheters (BGCs) for proximal flow arrest during neurointerventional procedures is limited due to incompatibility of these catheters with largebore aspiration catheters and difficulty in device navigation. The objective of our study was to describe the use of Walrus (Q'Apel Medical, Fremont, CA), a new 8-French (F) BGC, with a variety of aspiration catheters and procedures requiring flow arrest.

Methods Consecutive cases using Walrus BGCs for proximal flow arrest during mechanical thrombectomy for acute stroke cases was recorded. Procedure indication, vessel occlusion site, technique, first-pass effect (modified thrombolysis in cerebral infarction score of $2 \mathrm{C}$ or 3 after first recanalization attempt), and complications were recorded and evaluated statistically.

Results Our study included 57 patients: all (100\%) underwent mechanical thrombectomy. Besides mechanical thrombectomy, the Walrus BGC was used in conjunction with the following techniques: stent retrieval in 2 patient (3.5\%), Solumbra in 41 (71.9\%), and aspiration-first in 14 (24.6\%). Eight different aspiration catheters were used in 56 of these 57 procedures. First-pass effect was achieved in $36(63.2 \%)$ of 57 procedures. Four cases $(7.0 \%)$ experienced intraoperative complications and $2(3.5 \%)$ died during in-hospital stay.

Conclusion Our study demonstrates Walrus BCG as an excellent $8 \mathrm{~F}$ navigable guide catheter compatible with most available aspiration catheters. With a larger inner diameter and compatibility with most available aspiration catheters, it can be used to achieve proximal flow arrest during mechanical thrombectomy and possibly for other neurointervention procedures in the future.

Abbreviations and acronyms ADAPT, a direct aspiration first pass technique; BGC, balloon guide catheter; F, French; FPE, first-pass effect; ICA, internal carotid artery; ID, inner diameter; mFPE, modified first-pass effect; mRS, modified Rankin scale; mTICI, modified thrombolysis in cerebral infarction; OD, outer diameter; STRATIS, Systematic Evaluation of Patients Treated with Neurothrombectomy Devices for Acute Ischemic Stroke

Disclosures R. Dossani: None. M. Waqas: None. A. Baig: None. D. Popoola: None. J. Cappuzzo: None. H. Rai: None. A. Monteiro: None. A. Levy: None. E. Hashmi: None. J. Davies: None. E. Levy: None. A. Siddiqui: None.

\section{E-131 TRANSFEMORAL VERSUS TRANSRADIAL APPROACH FOR CEREBRAL ANGIOGRAPHY: A PATIENT PREFERENCE SURVEY}

${ }^{1} \mathrm{~J}$ Cappuzzo, ${ }^{1} \mathrm{~A}$ Aguirre, ${ }^{1} \mathrm{~A}$ Monteiro*, ${ }^{2} \mathrm{~K}$ Vakharia, ${ }^{1} \mathrm{~N}$ Ruggiero, ${ }^{1} \mathrm{M}$ Waqas, ${ }^{1} \mathrm{R}$ Dossani, IJ Davies, 'A Siddiqui, ${ }^{1} E$ Levy. ${ }^{1}$ Neurosurgery, University at Buffalo Neurosurgery, Buffalo, NY; ${ }^{2}$ Neurosurgery, Mayo Clinic, Rochester, NY

10.1136/neurintsurg-2021-SNIS.226

Introduction The neurointerventional field is going through a paradigm shift towards a radial first approach, following lessons from interventional cardiology. The transradial approach for endovascular interventions have certain advantages over the transfemoral approach, such as less complications related to access-site, less post procedural pain, earlier deambulation and shorter hospital stay. To the best of our knowledge, there are no studies assessing the patients' preference for one approach over another.

Methods Our institution's prospectively maintained database of cerebral digital subtraction angiographies was retrospectively searched to identify patients who underwent both transradial and transfemoral approaches between January 2011 and January 2021. We included patients who underwent both approaches in distinct occasions within time period of the study and those who required switching from one approach to another during the same procedure. Electronic medical records of each patient were accessed to extract the phone number provided for clinical follow-up. Three medical students conducted phone interviews using a standardized questionnaire. Three contact attempts with 3 days of interval was made for each patient before considering them as lost to follow-up. Patients were interviewed with 2 major questions. The first was regarding their approach of choice for an eventual next procedure, having the options of radial, femoral or no preference. The second question addressed the reasons behind their choices, being able to choose as many as necessary from the following common complaints related to a cerebral angiogram: pain, bruising, complications, recovery time, mobility, failure of one approach and comfort of puncturing the respective area. If no preference, patients were asked if they think it is a physician's decision or if both approaches were similar to them.

Results Forty-four patients were successfully contacted. In response to the initial question "If you were to undergo a cerebral angiogram again, would you rather receive a radial or a femoral approach?", 70.4\% answered "Radial”, 20.5\% answered "Femoral" and 9.1\% said "no preference". From those patients who chose "Radial", the subsequent question "What reasons influenced your answer?" was answered as following: pain $(48.4 \%)$, bruising $(51.6 \%)$, complications (25.8\%), recovery time (67.8\%), mobility (29\%), failure of the other approach (0\%) and comfort of puncturing the 